\title{
Hiperatividade: Doença ou Essência Um Enfoque da Gestalt-Terapia
}

Hiperactivity: nature or disease? Understanding ADHD in a Gestalt perspective

Sheila Antony \&

Jorge Ponciano Ribeiro

Universidade

de Brasilia
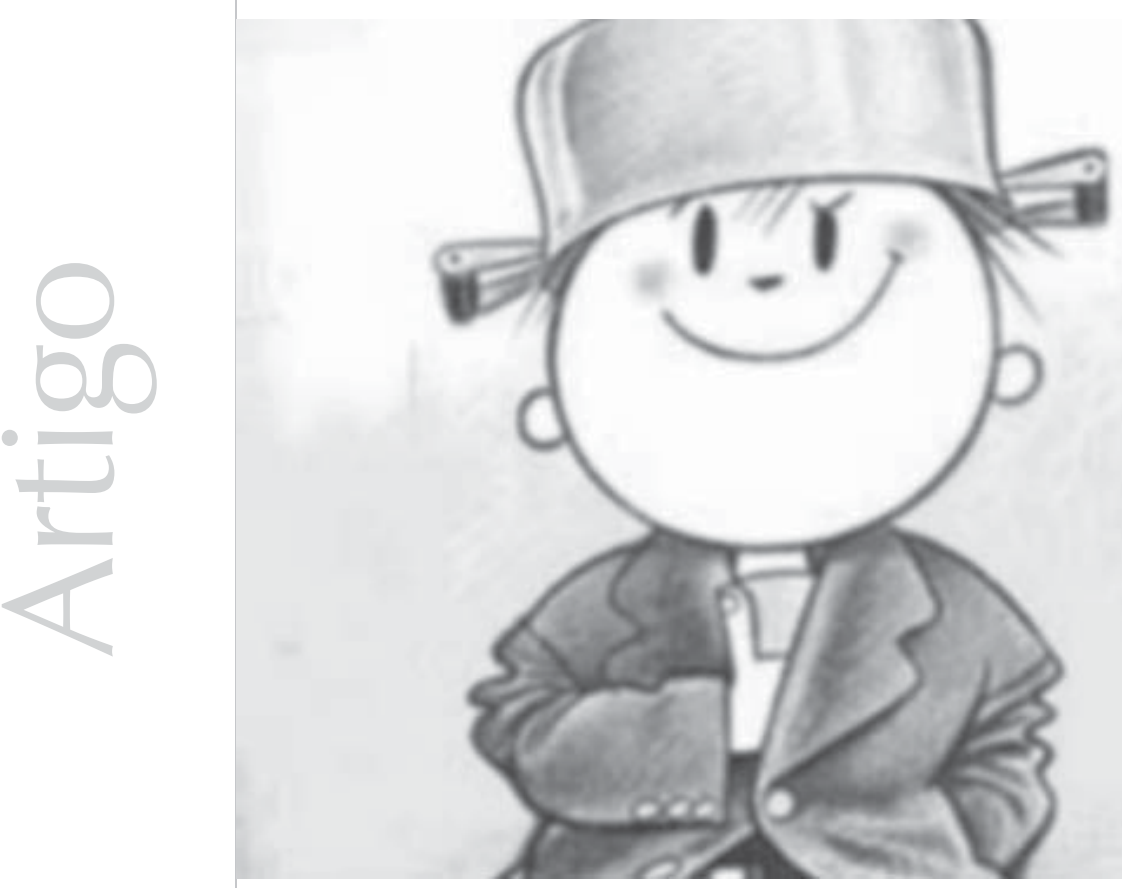


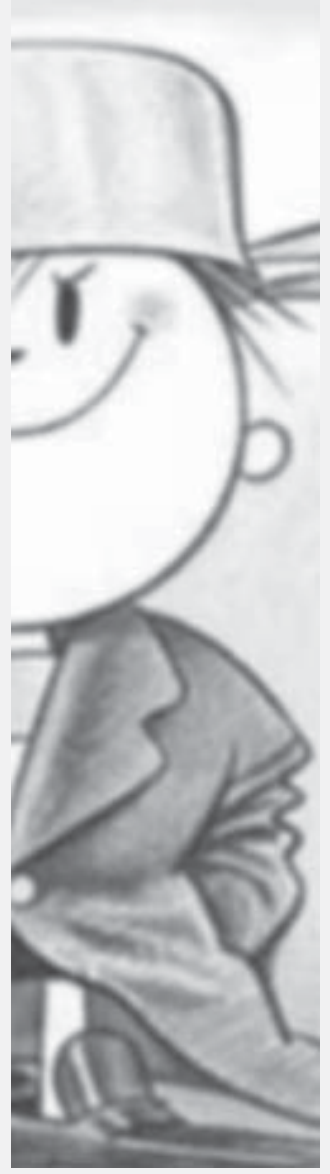

Resumo: Este trabalho discute a hiperatividade considerando a metáfora do corpo da criança e o seu funcionamento psicológico, de forma a esclarecer se a sua expressão constitui doença ou um modo próprio de ser. O transtorno de déficit de atenção/hiperatividade (TDAH) tem sido extensivamente investigado em pesquisas que visam aprimorar os critérios diagnósticos e conhecer sua etiologia. Poucos estudos são orientados para elucidar a dimensão psíquica da criança hiperativa. A Gestalt-Terapia é uma abordagem fenomenológico-existencial assentada em teorias holísticas que reconhecem a multidimensionalidade do humano, enfocando a relação (o contato) como ontológica à existência humana.

Palavras-chave: TDAH, hiperatividade, Gestalt.

\begin{abstract}
This work argues hyperactivity considering the body metaphor and the child psychological functioning in order to understand its expression as disease or essence. Attention deficit hyperactivity disorder (ADHD) has been extensively investigated in research that aim to improve diagnostics criteria and know its etiology. Few studies are oriented to elucidate the psychological dimension of the hyperactive child. GestaltTherapy is a phenomenological-existential approach supported on holistic theories that recognize the human multidimensionality, focalizing relation (contact) as ontological to human nature.
\end{abstract}

Key words: DAHD, hyperactivity, Gestalt.

A tendência do pensamento científico moderno começa a sinalizar uma mudança na concepção de saúde e doença. A nova noção de doença apresenta uma perspectiva de múltipla causalidade, renunciando à idéia antiga de que há apenas um único fator etiológico. Salienta a influência ambiental nas ações e no comportamento do indivíduo e a importância da subjetividade nas formas de manifestação da patologia.

A Gestalt-Terapia (GT) é uma abordagem fenomenológico-existencial com uma visão holística de doença. Compreende o adoecer como resultante de uma desarmonia relacional entre pessoa e ambiente, que formam uma unidade indivisível. Ribeiro (1997, p. 36) pronuncia: "A doença é relacional. Não existe doença em si. Doença é fenômeno como processo; como dado, existe em alguém, e não como realidade em si mesma". Tellegen (1984) expressa que é necessário detectar a configuração específica com que se articulam as partes de um todo em cada situação concreta, de modo que o terapeuta possa apreender a forma encontrada por esse indivíduo de estar-no-mundo e o seu modo próprio de adoecer. O enfoque gestáltico, assim, visa ir além da descrição dos sintomas, busca o sentido da patologia e as vivências subjetivas da pessoa adoecida.
Era uma vez um menino maluquinho Ele tinha o olho maior do que a barriga Tinha fogo no rabo Tinha vento nos pés Umas pernas enormes lque davam para abraçar o mundo) E macaquinhos no sótão lembora nem soubesse o que significava macaquinho no sótão)

Ele era um menino impossível Ele era muito sabido Ele sabia de tudo A única coisa que ele não sabia Era como ficar quieto ....

Menino Maluquinho Ziraldo 
A hiperatividade tem sido extensivamente investigada do ponto de vista daquilo que é o transtorno, com um interesse específico direcionado para os critérios diagnósticos e a etiologia, onde, muitas vezes, os pesquisadores se referem à criança como o transtorno. Inúmeras pesquisas têm sido guiadas para encontrar uma causa biológica específica que explique o transtorno de déficit de atenção/hiperatividade (TDAH); contudo, evidências conclusivas de lesão ou disfunção neurofisiológica são pouco substanciais e continuam incertas. Conforme dito por Debroitner e Hart (1997, p.2 ):

"Aqueles que ainda hoje investem na idéia de que o TDAH é uma doença (invisível) do cérebro estão buscando uma explicação simples para um distúrbio que é complexo e multidimensional. Acreditamos que a nossa obsessão nacional pela genética como fator para explicar as disfunções sociais e psicológicas encontrou seus limites com o TDAH".

A enorme controvérsia quanto à etiologia e aos aspectos primários dessa síndrome apontam para a não obtenção da essência verdadeira daquilo que define esse quadro comportamental como entidade nosológica. Sabemos que as descrições nosográficas revelam apenas um conhecimento empírico da doença, faltando a compreensão daquilo que está além da forma, da aparência. Nesse intuito, a realização de minha dissertação de mestrado visou buscar o significado e o sentido da hiperatividade através do conhecimento dos processos psicológicos e relacionais das experiências subjetivas vividas por essa criança.

\section{Principais características e dificuldades básicas do TDAH}

Essa síndrome já recebeu diversas nomenclaturas, e parte da sua controvérsia se deve a essas mudanças na terminologia, alterações que refletiram tendências históricas na conceitualização da etiologia e nos aspectos essenciais do transtorno.

Ao longo de décadas, o meio científico esteve em busca de distinguir a característica primária que define o transtorno. Alguns autores apontaram a inquietação como o elemento central, enquanto outros destacaram a dificuldade em regular a excitação da atenção. Em 1994, o DSM-IV (Associação Psiquiátrica Americana) cunhou o termo "transtorno de déficit de atenção/hiperatividade" em substituição a "distúrbio de déficit de atenção por hiperatividade" (DSM-III-R, 1987), considerando a desatenção, a hiperatividade e a impulsividade como as condições principais. É válido destacar que a CID-10 emprega o termo "transtorno hipercinético", enfatizando mais a agitação psicomotora. Não nega a desatenção, mas justifica que a inclusão de crianças sonhadoras e apáticas nesse quadro introduz diferentes problemas e comportamentos a serem considerados.

Em nossa pesquisa, a desatenção foi descrita como dificuldade na atenção concentrada, distração (distintos estímulos ambientais distraem a criança com facilidade) e atenção difusa (presta atenção em muitas coisas ao mesmo tempo), que leva a problemas de memória e de pensamento. É dito, contudo, pelos pais e professoras, que essas crianças são capazes de se concentrarem horas em uma atividade que apreciam e em que são habilidosas (videogame, pintar, desmontar carrinhos) e que prestam atenção em tudo e em todos, mas são incapazes de se concentrar nas aulas e tarefas escolares.

Conforme Paim (1979, p.133), a atenção é um "processo psicológico mediante o qual concentramos nossa atividade psíquica sobre determinado objeto, a fim de fixar, definir e selecionar as percepções, as representações, os conceitos e elaborar o pensamento". Requer uma intencionalidade da consciência, onde a atenção voluntária supõe um esforço mental 
para orientar a atividade psíquica em direção a um estímulo e mantê-lo dentro do campo perceptivo consciente. Quando a criança mostra interesse em algumas situações ou objetos, faz uso das funções da atenção (discriminar, selecionar, fixar) e confirma que o ato da atenção não é puramente cognitivo, mas depende de fatores motivacionais e afetivos subjacentes que interferem na escolha dos objetos. Todo ato de percepção revela um processo de "atenção seletiva" e "desatenção seletiva". O problema da criança hiperativa, portanto, reside na manutenção da atenção que é responsável pela elaboração do pensamento.

Atenção, pensamento e memória estão intimamente interligados. Segundo as teorias da psiconeurologia, a fraca capacidade em manter a atenção concentrada interfere no processo de organização e elaboração do pensamento que afeta a retenção de dados na memória. Segundo as professoras, as crianças hiperativas apresentam dificuldades no processamento das informações, na organização e execução do pensamento (escrever e interpretar) e revelam problemas na memória de associação ("tem ótima memória para algumas coisas, mas esquece logo o que foi ensinado"). Concluímos que a fraca capacidade em sustentar a atenção ocorre devido a sua hiperatenção, ligada à rápida percepção ambiental, que acelera o fluxo de suas idéias e, assim, prejudica o processamento das informações e sua posterior assimilação e compreensão. Quanto maior a quantidade de dados de informação e mais complexa a sua natureza, mais difícil organizar as idéias, o que leva a uma falha na memória seqüencial (aquela que associa os dados).

A dificuldade na inibição dos impulsos leva a criança a agir com uma prontidão imediata ("Sinto, logo ajo"), sem medir as conseqüências ou planejar suas ações, mostrando que ela é pouco capaz de interiorizar ${ }^{1}$ seus sentimentos e fazer uso do pensamento reflexivo. A impulsividade psicomotora faz com que a criança não obedeça, não cumpra as regras, não respeite as fronteiras com o outro, não espere a sua vez para falar ou agir, não consiga adiar a gratificação de seus desejos, apresente forte reatividade emocional, aparentando ser uma criança imatura e instável emocionalmente.

A hiperatividade como característica marcante distingue a criança por estar em constante movimentação corporal durante a execução de uma tarefa e até quando está sem um fazer. Manifesta uma atividade contínua de balançar os pés ou as pernas, mexer em objetos a sua frente, mudar a postura corporal enquanto está sentada. Aparentemente, não tem domínio sobre seu corpo (é o corpo que a domina), e suas ações parecem involuntárias, manifestando um desencontro entre o sentir e o pensar. Ajuriaguerra e Marcelli (1986) afirmam que a instabilidade motora é a figura psicomotora que se destaca de um fundo desorganizado. E qual será esse fundo desorganizado?

O campo da psicomotricidade estuda o movimento humano como o primeiro instrumento na construção do psiquismo e aponta com grande ênfase a ação recíproca entre movimento, emoção, indivíduo e ambiente. Em uma nova ótica epistemológica, o olhar não está mais situado apenas no motor, num corpo instrumental, mas "num corpo em movimento que, na medida em que se desloca, constrói a realidade e a própria capacidade intelectiva, que sente, que se emociona e cuja emoção manifesta-se tonicamente" (Levin, 2001, p. 31). Corpo, motricidade e emocionalidade formam uma unidade e totalidade em si mesmas.

A psiconeurologia descreve que, evolutivamente, o movimento organiza o pensamento até ele superar a própria motricidade, quando o pensamento passa a coordenar o movimento. Há um processo "num corpo em movimento que, na medida em que se desloca, constrói a realidade e a própria capacidade intelectiva, que sente, que se emociona e cuja emoção manifestase tonicamente"

Levin
1 Le Boulch (1988) define a função de interiorização como a capacidade de deslocar a percepção do meio ambiente para o próprio corpo a fim de levar à tomada de consciência de si. 
cronológico hierárquico da experiência que vai da sensação à percepção até chegar à simbolização, onde o movimento é anterior à aquisição do pensamento estruturado, da linguagem interiorizada e das praxias. Fonseca (1995) discorre com muita clareza sobre esse assunto: "A linguagem segue a motricidade, tem origem nela, só depois é que a guia e regula, sendo vista como poderoso instrumento da atenção seletiva para o exterior(...). Antropologicamente, o ser humano só atinge as suas funções psíquicas superiores por efeito da sua psicomotricidade" (pp. 52-75). A hipercinesia, assim, parece substituir a falta do pensamento organizado, da elaboração psíquica, onde o motor torna a relação com o mundo da ordem do concreto, havendo pouco lugar para a simbolização. segue a motricidade, tem origem nela, só depois é que a guia e regula, sendo vista como poderoso instrumento da atenção seletiva para o exterior(...). Antropologicamente, o ser humano só atinge as suas funções psíquicas superiores por efeito da sua psicomotricidade"

Fonseca
É o sujeito, portanto, que nos fala através do seu corpo, das variações tônico-motoras, do movimento, dos gestos, que são representantes de uma organização psíquica. Eis o desafio que nos lança a criança hiperativa com seu corpo em contínuo movimento.

\section{A metáfora do corpo}

A história da constituição da subjetividade humana tem início com o "eu corporal" até chegar ao "eu psíquico". O desenvolvimento do eu corporal se dá mediante a evolução do conhecimento corporal, caminho para uma autoconsciência que integra as sensações, percepções e funções do corpo. O eu-corpo nasce das sensações internas e da superfície do corpo em interação com o mundo e o outro. As coisas aparecem dos movimentos do corpo que tornam visíveis e sensíveis as ações dos estímulos. É a partir do meu corpo que descubro o mundo, interajo, experimento sensações e situações, expresso-me, percebome e percebo as coisas até chegar à interiorização das minhas sensações, que me dará consciência da indivisibilidade de mim e do meu corpo. A autodescoberta é "uma autoposse indivisível da nossa existência completa" (Alves, 2003, p. 54 ), é o reconhecimento de que eu habito meu corpo. A noção de corpo da criança tem início com a percepção das partes isoladamente para depois chegar à percepção do corpo total, que mantém a funcionalidade entre as partes. Em 1920, Head usa a expressão esquema corporal para referir-se à tomada de consciência das partes do corpo e suas funções, provenientes das experiências proprioceptivas e exteroceptivas. O esquema corporal (como noção de forma organizada) é que irá regular a postura, o equilíbrio e a orientação no espaço, possibilitando o domínio corporal. A criança que domina seu corpo desenvolve um sentimento de autoconfiança, de competência, que coordena a sua conduta psicomotora e possibilita o refinamento motor, a precisão dos movimentos. O esquema corporal, ao ir-se constituindo, dá forma ao eu, que se torna unificado e diferenciado.

A criança, vivenciando o seu corpo, situa-se em relação ao espaço e aos objetos circundantes. Segundo Poppovic (citada por Alves, 2003, p. 69), "orientar-se no espaço é ver-se e ver as coisas no espaço em relação a si mesma", de forma a tomar consciência da relação de co-presença entre corpo e mundocoisas. Reconhecer-se enquanto corpo só é possível porque os outros têm também um corpo. O meu corpo é um meio de conhecer os outros corpos e de estes conhecerem o meu. É preciso que eu aprenda a considerar meu corpo como objeto para, em seguida, poder perceber o corpo-objeto alheio e ser por este objetivado. Wallon (1950) cunha o termo diálogo tônico para descrever as trocas tônico-afetivas que ocorrem na relação corpo a corpo entre mãe-bebê, que são a base das primeiras experiências emocionais. Ajuriaguerra e Marcelli (1986) lembram que modificações tônicas acompanham cada afeto e cada fato da consciência. Quando a mãe olha, fala, toca, acaricia o filho, comunica um estado emocional e uma afetividade que sensibilizam sensorialmente o bebê. A 
intercorporeidade, segundo Merleau-Ponty (2000), diz que o corpo vai ser relação com outros corpos semelhantes, onde o modo de relação com o mundo e o outro inclui a relação do corpo consigo mesmo. Assim, o indivíduo organiza, com seu corpo, uma compreensão do mundo e de si mesmo.

O conceito de imagem corporal conclui a evolução do eu corporal para o eu psíquico. Esse conceito fala do surgimento do "eu penso meu corpo" e da tomada de consciência do sentimento que a pessoa tem do seu corpo para si e para o outro. "A imagem corporal é a história constitutiva da subjetividade do corpo humano" (Levin, 2000, p. 154), sendo própria de cada um. É nesse momento que o indivíduo tem a vivência fundamental de unidade, de gestalt, de forma unida, saindo da representação de corpo-coisa para corpo-eu. O eu psíquico se faz crer quando o corpo torna-se sujeito que se comunica consigo interiormente: eu me sinto, eu me penso. Sou corpo tocante-tocado, desejado-desejante, vidente-visto, sendo, simultaneamente, sujeito e objeto. Merleau-Ponty (2000, p. 125) cita Husserl ao discursar sobre a intersubjetividade e a dialética do corpo: "Um indivíduo que só tivesse olhos não teria um conhecimento de si mesmo. Falta-lhe um espelho, faltam-lhe os outros". Levin (idem, p. 67) completa essa elucidação, dizendo: "A criança não pode se dar um ser, não pode se dar um nome, um corpo senão a partir do outro que a reconhece, confirma, deseja, significa, nomeia".

Portanto, o corpo de um sujeito tem um em si, um para si e um para o outro. O corpo não é um puro corpo. Revela um simbolismo de um eu singular e diferenciado cujo sentido transcende a si próprio por ser constituído pelo olhar de um corpo-outro situado no mundo.

\section{O enigma do corpo da criança hiperativa}

Vimos que o corpo em movimento, em relação, vivenciando a realidade, serve de base para o desenvolvimento motor, cognitivo e afetivo da criança. A nossa tarefa é decifrar o enigma do corpo da criança hipercinética, o que tem a dizer com a sua instabilidade corporal que não tem pausa, limite.

A metáfora do corpo revela o significado e o valor que se mostram em um significante (gesto, mímica do corpo), no qual todo movimento ou gesto tem um valor expressivo em si, para si e para o outro. Ao observar uma criança hiperativa, parece que é o corpo que a domina, que não tem posse do próprio corpo ou que o corpo não lhe pertence. Os movimentos do corpo da criança hipercinética são dados a ver a um outro que the dá o sentido de repugnante, inconveniente, errado, inapropriado. A criança hiperativa cresce ouvindo queixas, depreciações, críticas a respeito de seu corpo ("Você não fica quieto, não pára um instante. Que menino chato, desajeitado, não faz nada direito. Só me dá trabalho"). Assim, nas fases iniciais de constituição do eu, a imagem que consolida de si é a imagem que os outros têm dela, introjetando um conceito negativo do corpo-eu que nutre sentimentos de rejeição e inadequação.

A criança não sabe que há um dizer no seu fazer corporal, é o outro quem se queixa da hiperatividade. A patologia, então, é relacional. O distúrbio ou o sintoma emerge da relação, inclui o outro. Desse modo, o sintoma psicomotor se desenvolve com, para e pelo outro. O olhar do outro aparece controlando, antecipando a ação ("Cuidado! Você pode cair, se machucar, morrer. Não faça isso, não mexa nisso") até o ponto de cronificar o sintoma. A criança, na turbulência dos seus movimentos e de seu corpo, retém o ser olhado constantemente,
Para fazer entender essa relação da sensação e do corpo-eu que passa a se subjetivar, Husserl (citado porMerleau-Ponty, 2000a, p. 123) recorre a uma experiência do tato:

"Quando toco minha mão esquerda com minha mão direita, minha mão tocante apreende minha mão tocada como uma coisa. Mas, de súbito, dou-me conta de que minha mão esquerda começa a sentir (...). Como coisa fisica, ela continua sendo sempre o que é e, no entanto, é diferente segundo for tocada ou tocante. Assim eu me toco tocando, realizo uma espécie de reflexão, de cogito, de apreensão de si por si. Em outras palavras, meu corpo torna-se sujeito: ele sente". 
que confunde o seu espaço e o seu corpoeu. As mães comentam: "O meu filho não pode ficar um instante sozinho porque apronta, não tem limites, não tem noção de perigo". Esse constante olhar vigilante vem obstruir a originalidade dos desejos, vontades e necessidades da criança. O seu corpo passa a ser do outro que cuida, controla, domina e que não lhe confirma a alteridade, não aceita seu modo diferente de ser. $\mathrm{O}$ outro não reconhece a necessidade da criança em movimentar-se, proíbe o seu querer, recrimina o seu corpo desejante, instituindo o dilema da sua existência singular: "Eu sou inquieto, eu preciso me mexer, eu quero fazer do meu jeito, mas não posso, não me deixam ser assim. Eu tenho que ser como eles querem, mas não consigo e não aceito".

Em nossa vivência clínica, vemos que são as mães que se preocupam com a criança, que ficam a vigiá-la, a cuidar a mais, a cortar a sua ação. Em função desse olhar controlador, é criada uma relação de extrema dependência e necessidade mútua entre mãe-criança, onde é perdido o limite simbólico da diferenciação e discriminação entre um e outro, eu-não eu, fora-dentro, ausência-presença, longeperto. Nas palavras de Bergés (citado por Levin, 2000, p.159), "Tudo seria como se essas instabilidades representassem a busca incessantemente fracassada dos limites, como se o corpo carecesse de fronteiras". A criança movimenta seu corpo com medo de parar e cair no vazio da falta de uma forma que delineia e demarca o seu corpo-eu. No seu agir excessivo, está à procura da sua individuação e dissimula a necessidade de ficar longe dos olhos vigilantes da mãe para ganhar autonomia. Carece de uma noção sólida de si devido à ausência de uma imagem interna e externa confirmadora da sua essência.
A essência do TDAH revela, portanto, que a criança é confusa, não sabe bem o que fazer e o que pensar, vive à procura de si e de um sentido de vida. Nas palavras de uma mãe: "Ele parece uma barata tonta"! A hiperatividade vem mostrar-se mais como um sintoma na sua aparência, e, como todo sintoma, tem um caráter de defesa.

A partir dos resultados de nossa pesquisa anterior, cujo objetivo foi investigar o funcionamento psicológico da criança hiperativa, iremos apresentar a visão holísticorelacional-existencial da GT.

\section{A Gestalt-Terapia: uma visão dinâmica}

A Gestalt-Terapia (GT) é uma abordagem fenomenológico-existencial fundamentada em teorias de base sistêmico-holísticas que propiciam uma visão dinâmica e multidimensional do ser humano e do mundo.

Inserida nesse campo filosófico, tem uma compreensão ontológica da pessoa como ser-no-mundo, que vive a sua existência para o outro e com o outro. A existência, em um mundo compartilhado, anuncia a intersubjetividade como condição criadora do sujeito, cuja existência revela a busca permanente da constituição de sua essência. Por meio da fenomenologia, resgata o valor da experiência imediata como método descritivo das essências do fenômeno. A experiência vivida e observada como fenômeno que se revela a uma consciência, sem a prioris e juízo, é o dado de realidade original que põe em evidência o ser em situação cuja realidade é sempre construída pela experiência no mundo objetivo.

A partir de suas teorias de base (Psicologia da Gestalt, teoria do campo e teoria organísmica), 
a GT fundou uma visão holística calcada no conceito todo-parte, onde somente a totalidade contém o significado a partir das múltiplas interações existentes entre as partes e os campos. Compreende o comportamento humano como resultante da unidade campo organismo/ambiente, que mantêm entre si uma relação de reciprocidade. Assim, o indivíduo pode apresentar múltiplas possibilidades de comportamento e contato conforme o campo ao qual pertence em um dado momento.

A GT pretende compreender o funcionamento psicológico da pessoa a partir das trocas emocionais que ocorrem no "entre", na fronteira do contato, que propiciam a vivência das experiências subjetivas. Fritz Perls (1977) pensou saúde e doença dentro da concepção de fronteira de contato, espaço existencial onde o eu e o não-eu se experienciam e os eventos psicológicos acontecem. A relação de reciprocidade existente entre indivíduo e meio ressalta a influencia mútua ente si, cuja enunciação expõe: Eu afeto o mundo e sou afetado por ele; eu adoeço o mundo e sou adoecido por ele. Para a GT, não há lugar para o indivíduo encapsulado em si. A formação das patologias, portanto, é o caminho dos encontros e desencontros relacionais.

Situações onde ocorrem tensões e angústia podem produzir entraves no contato entre o indivíduo e o meio. Na perspectiva da Gestalt, doença significa bloqueios do contato originados por mecanismos psicológicos com funções defensivas que visam inibir a consciência de sentimentos, pensamentos, comportamentos que geram ansiedade e colocam em risco a relação com o outro significativo. Formam dinâmicas intra e inter-relacionais com padrões de comportamentos que levam o indivíduo a manter, no presente, gestalten inacabadas do passado, impedindo-se de realizar um contato saudável.

Perls, Hefferline e Goodman (1951/1997), inicialmente, descreveram o processo do contato como um todo unificado, representado em uma seqüência contínua de figura-fundo que tem origem numa vaga sensação que se delineia como figura, levando à mobilização de energia e a uma ação organizada que responde a uma necessidade emergente. $\mathrm{O}$ ciclo se fecha quando o organismo tem a experiência de satisfação plena, entrando em retraimento e colocando-se, em seguida, à disposição de uma nova figura. A interrupção sistemática e repetida do fluxo de formação e destruiçãa de figuras deixa gestalten abertas e necessidades não satisfeitas. Cada situação incompleta retém energia mental e física em torno de uma necessidade insatisfeita que exerce permanente pressão psíquica para sua realização e, assim, leva a pessoa a manter comportamentos repetitivos no presente.

O modelo adotado em minha pesquisa, que retrata o ciclo da experiência do contato, é de autoria de Ribeiro, J. (1997), nomeado de "Ciclo dos Fatores de Cura e Bloqueios do Contato" (figura 1), que reconhece nove fases do contato (fluidez, sensação, consciência, mobilização, ação, interação, contato final, satisfação e retirada) e nove mecanismos de bloqueio do contato (fixação, dessensibilização, deflexão, introjeção, projeção, proflexão, retroflexão, egotismo e confluência) como formas polares complementares, mostrando a dinâmica entre saúde e doença. 
Figura 1: Ciclo dos fatores de cura e bloqueio do contato

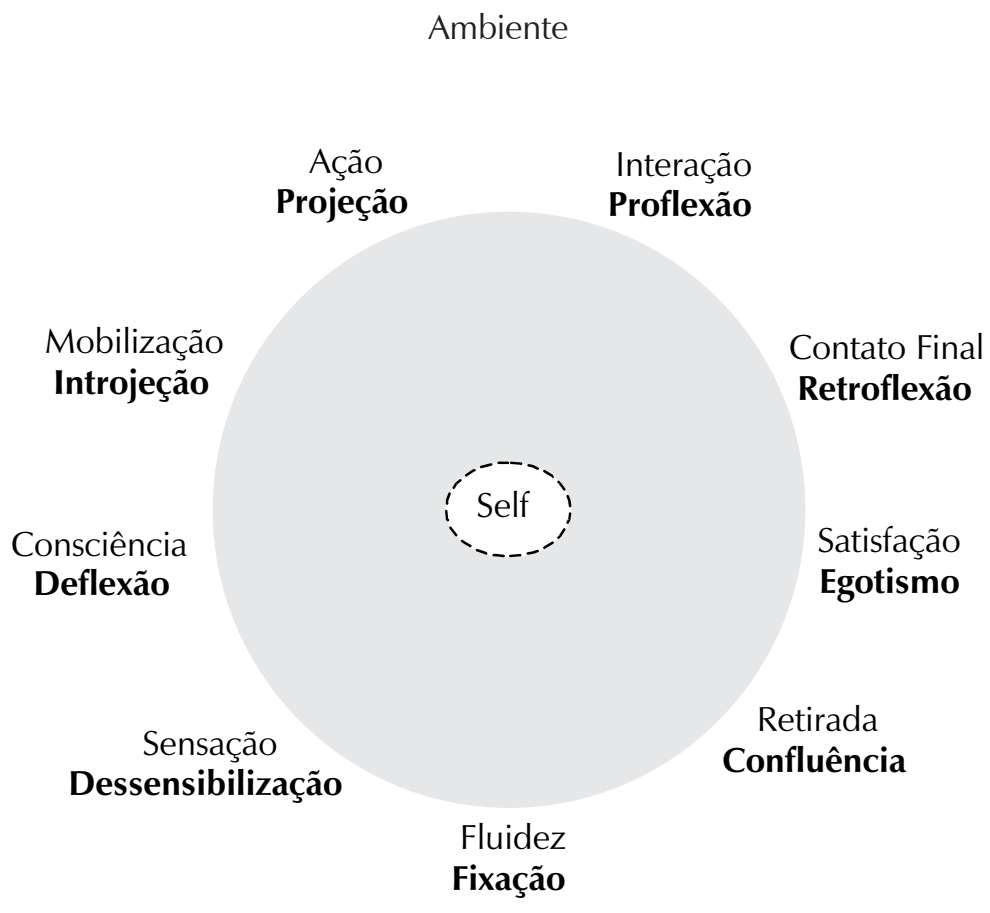

Partindo para elucidar como o TDAH se mostra na dimensão intrapsíquica da criança, estabelecemos, em nossa pesquisa, uma correlação entre os mecanismos psicológicos da GT, a análise interpretativa do Teste de Apercepção Temática - figura de animais (CATA) e as principais categorias obtidas da análise de conteúdo do discurso das professoras e dos pais.

A DEFLEXÃO aparece como o processo psicológico que define o transtorno e as manifestações comportamentais da criança. A inquietação e a hiperatenção (desatenção) revelam a mudança constante de atividade ou de objeto, que caracteriza um modo vago e superficial de fazer contato com as coisas e com os outros em razão da dificuldade em enfrentar situações de tensão e ansiedade. $\mathrm{O}$ oposto complementar da deflexão no ciclo é a consciência, significando que a criança carece da consciência de si mesma, de reconhecer a necessidade emergente, da capacidade de escolher o objeto que irá propiciar sua satisfação.

A PROJEÇÃO foi uma outra dinâmica encontrada. No ciclo do contato, isso representa um bloqueio na fase "ação". A criança não realiza uma ação apropriada no meio por possuir introjeções negativas (“Você é chato, não fica quieto. Você é desobediente. Você está sempre aprontando, fazendo coisas erradas"), que a impedem de agir conforme as suas necessidades genuínas e características próprias de personalidade. Os resultados do CAT-A revelaram que a criança vê o mundo como incompreensivo, agressivo, intolerante (o inimigo de quem precisa se defender), que não 
aceita o seu modo de ser agitado. Expressa uma percepção crítica sobre o seu comportamento agitado, julgando-se merecedora de punição com frases do tipo: "O cachorro não fica quieto, ele faz confusões. O ratinho fez alguma porcaria com ele. O macaquinho é muito sapeca, ele é aprontador". A criança, por conseguinte, vive um eterno conflito interno entre os "não deverias" e aquilo que é, originalmente, o seu modo de ser e agir, criando uma baixa autoestima oriunda de uma confusa imagem corporal que compromete a sua ação-interação.

O EGOTISMO emerge como o processo psicológico que forma a base da personalidade da criança, oriundo das categorias afetividade e determinação. Refere-se às características de onipotência e auto-referência da criança, ao seu modo imperativo e voluntarioso de agir (não aceita a opinião dos outros, quer fazer do seu jeito, mesmo que errado), a necessidade de ser o centro das atenções, a sua alta demanda de afeto, que a torna uma criança com uma intensa reatividade e vulnerabilidade emocional (chora com facilidade, sente muito ciúme, busca muito contato físico, é muito carinhosa). Para os pais e professoras, a criança possui uma carência afetiva difícil de ser suprida, destacando um outro paradoxo no seu funcionamento: déficit de afetividade X hiperemotividade. O pólo complementar no ciclo é a satisfação, indicando que a criança se encontra em estado permanente de insatisfação em suas trocas com o meio. Por outro lado, apontam uma atitude não egoísta, um modo prestativo de ser, dando o que é seu quando o outro precisa, fazendo uso da PROFLEXÃO (eu faço aos outros aquilo que gostaria que fizessem comigo) como mecanismo de compensação.

Em conclusão, os processos do contato básicos que organizam o funcionamento psicológico da criança hiperativa são: DEFLEXÃO, PROJEÇÃO, EGOTISMO. A combinação dinâmica desses três mecanismos revela os seguintes processos internos e relacionais: a criança deflete por meio da inquietação e da desatenção. Ao defletir com uma ação motora excessiva, que ocorre em simultaneidade com a atenção difusa, a criança passa a comportar-se de forma inapropriada, sem atender à necessidade prioritária. Sua ação desorganizada advém da PROJEÇÃO, ao lançar no ambiente partes de si consideradas inaceitáveis (introjetos tóxicos) que, por sua vez, criam perturbação na qualidade da interação. Nesse ponto, a criança recorre à PROFLEXÃO como mecanismo saudável para reparar as suas condutas inadequadas, sendo prestativa na esperança de receber em troca aprovação e afeto para compensar seu "déficit de afetividade". O EGOTISMO revela a luta da criança (já que não é aceito o seu modo de ser) para impor sua identidade perante o mundo. Assim, seu modo de agir, pensar e sentir reflete: "Já que o mundo não me aceita como eu sou, não me compreende e não atende as minhas necessidades de afeto, eu mesma vou me nutrir, vou fazer o que eu quero. Ninguém manda em mim".

Analisando a criança hiperativa do ponto de vista dos fatores de cura do ciclo do contato, temos: a inquietação e a desatenção significam que a criança está em permanente processo de fluidez, em contínuo movimento, em busca de novos estímulos. Há um excesso de excitação que cria um alto nível de mobilização de energia para a execução da ação, a qual é efetuada pronta e impulsivamente. Mantém um contato superficial com as coisas, trocando incessantemente o foco da atenção ou ação de um objeto a outro prematuramente, sem manter a continuidade até o fechamento da gestalt. A criança não se satisfaz plenamente, não entra em retraimento, não alcança a harmonia organísmica, experienciando um estado permanente de insatisfação. A criança vive, assim, um processo interminável de busca da própria auto-regulação, onde a hiperatividade e a desatenção disfarçam a condição essencial da síndrome que reflete uma busca alienada de objetivos e de sentido para a existência.

Uma vez que a atenção acompanha o fluxo da excitação, não se deveria diagnosticar hiperatividade sem sintomas de desatenção 
Cresceu e virou um cara legal!

Aliás, virou o cara mais legal do mundo!

Mas, um cara legal mesmo!

E foi aí que todo mundo descobriu

que ele não tinha sido um menino maluquinho

Ele tinha sido era um menino feliz!

Menino Maluquinho Ziraldo como indicado no DSM-IV. Caso existam apenas sintomas de desatenção, deve-se reconhecer uma tipologia e uma categoria nosológica diferenciada, o que nos leva a propor uma nova terminologia: transtorno de hiperatividade/ atenção.

\section{Conclusão}

A hiperatividade representa um alto nível de excitação organísmica cujo elevado fluxo de energia faz a criança funcionar em "alta voltagem", respondendo ao mundo com HIPERATIVIDADE, HIPERATENÇÃO e HIPEREMOTIVIDADE. A criança hiperativa é constitucionalmente hiperativa. Sua hiperatividade, sua hiperatenção, sua hiperemotividade são constitutivos dinâmicos de seu ser-no-mundo. Sendo assim, ela não está hiperativa, ela é hiperativa, porém, como ser-derelação ontologicamente em permanente mudança; ela é, no mundo, um ser em processo à procura de sua atualização existencial.

A criança não vê a sua inquietação como doença, mas considera-a um problema. No CAT-A, um menino comenta que "o macaco nasceu com problema de chatice". Um outro diz que o cachorro tem um "negócio no corpo, uma deficiência moral que não o deixa pensar direito". A criança revela, aqui, a sua dificuldade em controlar o corpo e os pensamentos, levando-a a fazer coisas que contrariam a sua vontade e as expectativas externas.

A inquietação e a desatenção refletem um contato superficial consigo e com o outro cujo intuito é defender-se daquilo que lhe é angustiante sentir e pensar: o outro crítico, intolerante, e a consciência confusa, depreciativa, de si mesma.

A criança hiperativa experimenta os dois extremos (lentidão no pensamento $x$ rapidez na percepção, hiperatenção $x$ déficit de atenção, hiperemotividade $x$ déficit de afetividade), revelando uma dialética paradoxal de fenômenos onde o "excesso cria a deficiência", em uma função oposta complementar.
O caminho da saúde demanda um trabalho a ser feito com os pais, as professoras e a própria criança, de modo a promover melhor integração social, oferecer um suporte educacional mais apropriado e um tratamento mais humano e respeitoso. É fundamental criar um modelo pedagógico e interacional junto aos pais e professoras que os faça despertar para os talentos oriundos dessa alta excitabilidade e lhes permita conviver criativamente com essa criança. A palavra transtorno coloca a hiperatividade totalmente no domínio da patologia, o que não é correto. Essa criança, por ser mais sensorial e motora, é mais intuitiva, criativa, afetuosa e "fazedora".

Sugerimos aos adultos interessarem-se mais pelas coisas que a criança sabe fazer, por aquilo que ela tem de positivo, e não somente por suas deficiências. Enfatizar mais as qualidades do que os supostos déficits é o melhor meio de ajudá-la a superar as dificuldades e desenvolver suas potencialidades inatas. Em nossa pesquisa, oferecemos diversas propostas psicopedagógicas para uso dos pais e professoras.

O caminho da saúde, por parte da criança, é o resgate da consciência de seu corpo próprio, de seus pensamentos e sentimentos, de forma a tornar-se uma presença consciente. É aprender a assumir responsabilidade por suas escolhas e ações, ser capaz de criar metas e objetivos para dar sentido a sua vida, saber hierarquizar suas necessidades para poder ajustar-se criativamente ao meio.

A totalidade da condição humana está inserida em uma totalidade mais ampla que forma a realidade holística relacional. O TDAH está nas crianças assim como também está no mundo, com seu ritmo acelerado, oferecendo múltiplas informações cuja realidade muda mais rápido que nossa percepção. O todo está na parte e a parte está no todo. Somos a sociedade que produzimos e que nos produz. 


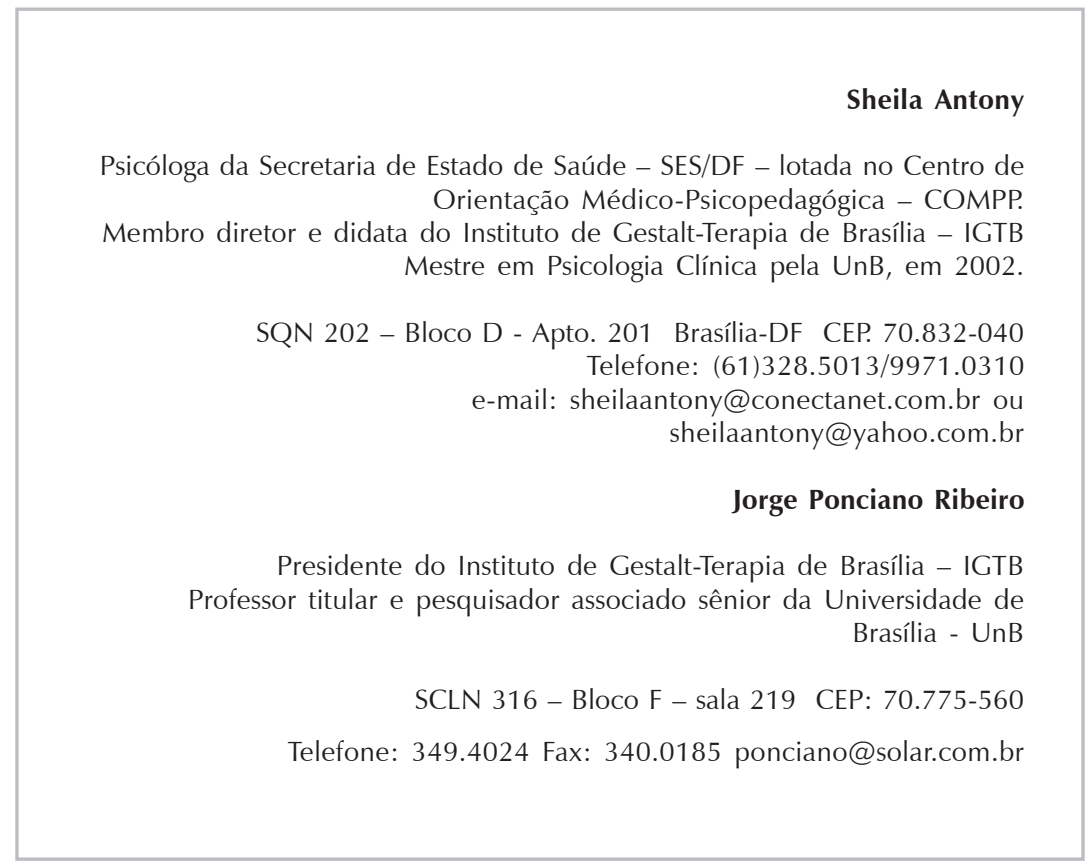

Recebido 8/03/04 Reformulado 22/05/05 Aprovado 30/06/05

AJURIAGUERRA, J. \& MARCELLI, D. Manual de Psicopatologia Infantil. Trad. A . E. Filman. Porto Alegre: Artes Médicas; São Paulo: Masson, 1986.

ALVES, F. Psicomotricidade: Corpo, Ação e Emoção. Rio de Janeiro: Wak, 2003.

AMERICAN PSYCHIATRIC ASSOCIATION. DSM-IV. Manual Diagnóstico e Estatístico de Transtornos Mentais. $4^{\mathrm{a}}$ ed. Porto Alegre: Artes Médicas Sul, 2000.

ASSUMPÇÃO Jr., F. Psiquiatria da Infância e da Adolescência. São Paulo: Santos, 1994

BARBOSA, G. A., GAIÃO, A. \& DI LORENZO, W. F. Transtornos Hipercinéticos: uma Revisão Crítica. Neurobiologia, vol. 59, 4, 1996, pp. 12-136.

BENCZIK, E. Transtorno de Déficit de Atenção/Hiperatividade: Atualização Diagnóstica e Terapêutica. $2^{\text {a }}$. edição. São Paulo: Casa do Psicólogo, 2000.

CLARKSON, P. Gestalt Counselling in Action. London: Sage, 1989.

DEBROITNER, R. \& HART, A. Moving Beyond ADD/ADHD - the Book. (1997) Retirado em 07.02.2001 em (http:// www.magicnet.net).

FONSECA, V. Manual de Observação Psicomotora: Significação Psiconeurológica dos Fatores Psicomotores. Porto Alegre: Artes Médicas, 1995.

HALLOWELL, E. \& RATEY, J. Tendência à Distração: Identificação e Gerência do Distúrbio do Déficit de Atenção da Infância à Vida Adulta. Rio de Janeiro: Rocco, 1999.

LE BOULCH, J. O Desenvolvimento Psicomotor: do Nascimento até os 6 Anos. Porto Alegre: Artes Médicas, 1988.
LEVIN, E. A Clínica Psicomotora: o Corpo na Linguagem. 4 ed. Petrópolis: Vozes, 2001.

LIMA, S. A Criança Hiperativa como uma Totalidade em Ação: uma Visão Gestáltica segundo a Teoria do Ciclo do Contato. Dissertação de Mestrado. Universidade de Brasília, Brasília, 2002.

MERLEAU-PONTY, M. ANatureza. Trad. A. Cabral. São Paulo: Martins Fontes, 2000

ORGANIZAÇÃO MUNDIAL DE SAÚDE. Classificação de Transtornos Mentais e de Comportamento da CID-10 Descrições Clínicas e Diretrizes Diagnósticas. Porto Alegre: Artes Médicas, 1993

PAIM, I. Curso de Psicopatologia. $4^{\mathrm{a}}$.ed. São Paulo: Ciências Humanas, 1979

PERLS, F., HEFFERLINE, R. \& GOODMAN, P. Gestalt-Terapia. Trad. F. R. Ribeiro. São Paulo: Summus. (1951) 1997.

PERLS, F. AAbordagem Gestáltica e Testemunha Ocular da Terapia. $2^{\mathrm{a}}$. ed. Rio de Janeiro: Zahar, 1977.

RIBEIRO, J. Gestalt-Terapia: Refazendo um Caminho. São Paulo: Summus, 1985.

O Ciclo do Contato. São Paulo: Summus, 1997.

TELLEGEN, T. Gestalt e Grupos: uma Perspectiva Sistêmica. São Paulo: Summus, 1984

WALLON, H. L'Évolution Psychologique de l'Enfant. Paris: Armand Collin, 1950. 